\title{
A Role of Multiparametric Magnetic Resonance Imaging on Biochemical Reccurences after Radical Prostatectomy
}

\author{
Mustafa Ozan Horsanali*, Huseyin Eren, Eyup Dil, Yusuf Onder Ozsagir and Ahmet Onur Yuksel \\ Department of Urology, TC Saglik Bakanligi Recep Tayyip Erdogan University, Turkey
}

Submission: January 22, 2018; Published: March 07, 2018

*Corresponding author: Mustafa Ozan Horsanal, Department of Urology, TC Saglik Bakanligi Recep Tayyip Erdogan University, Rize, Turkey, Tel: 00905079942217; Email: drozanhorsanali@yahoo.com

\begin{abstract}
Radical prostatectomy is one of the most effective curative treatment options for the men diagnosed a localized prostate cancer. After radical prostatectomy, approximately $30 \%$ of males develop biochemical recurrences. About one third of patients with biochemical recurrence eventually develop metastatic disease and approximately one in five will die because of prostate cancer. Traditional technics such as computerized tomography, transrectal ultrasonography and digital rectal examination have less sensivity and spesifity to detect local recurrence after radical prostatectomy. There are increasing evidence that multi-parametric MRI is an effective imaging method in detecting local recurrence of prostate cancer after radical prostatectomy. The purpose of this article is to review the role of multi parametric-MRI in determining local recurrence of prostate cancer in patients after radical prostatectomy.
\end{abstract}

Keywords : Prostate cancer; Radical prostatectomy; Mp-MRI; Biochemical recurrence

Abbreviations : RP: Radical Prostatectomy; Pca: Prostate cancer; PSA: Prostate-Specific Antigen; BCR: Biochemical Recurrence; sRT: salvage Radiotherapy; mp-MRI: Multiparametric Magnetic Resonance Imaging; DCE-MRI: Dynamic Contrast-Enhanced Imaging; MRSI: MR Spectroscopic imaging; DWI: Diffusion-Weighted Imaging; T2WI: T2-Weighted Images; NCCN: National Comprehensive Cancer Network

\section{Introduction}

Prostate cancer is the most common malignancy in the male genitourinary system and radical prostatectomy (RP) is an one of most effective and curative treatment alternative for the selected patients with diagnosed prostate cancer (PCa) assuming with presence of appropriate prognostic features [1]. After RP, PSA levels are measured at undetectable levels $(<0.01 \mathrm{ng} / \mathrm{mL})$ within $2-3$ weeks. An increase in serum prostatespecific antigen (PSA) levels after RP for localized PCa is defined as biochemical recurrence (BCR). Criteria for BCR varies according to therapy. Generally, BCR is defined as an increase in PSA values exceeding 0.2ng/dL threshold after RP [2]. Different BCR ratios are reported after RP and approximately $30 \%$ of men experience BCR and $95 \%$ of recurrences developed in the first 5 years [3-5]. About one-third of patients with BCR are suffering from metastatic disease, and approximately one-fifth die from PCa [6]. Early diagnosis and treatment of BCR is essential to prevent metastatic disease, and imaging modalities play a key role in distinguishing local and metastatic recurrence in patients with BCR. Administering salvage radiotherapy (sRT) is recommended to the men with poor prognostic factors such as positive surgical margin, seminal vesicle invasion, extra prostatic extention and high Gleason scores in pathological examination after RP $[7,8]$. European Urological Guidelines recommend early sRT for a total dose of 66 Gy when PSA levels $<0.5 \mathrm{ng} / \mathrm{ml}$. Active surveillance and delayed sRT may be an alternative treatment option for selected patients with good prognostic factors (pT3a, time to BCR $>3 y$ r, PSA doubling time $>12 \mathrm{mo}$, Gleason score 7) [9]. Because the lack of optimal imaging test to distunguish local disease from distant metastasis in patients with low PSA levels after RP, imaging is not recommended before salvage. Recently, several investigations have shown promising results of multiparametric magnetic resonance imaging (mp-MRI) in detecting local recurrence using dynamic contrast-enhanced imaging (DCE-MRI), MR spectroscopic imaging (MRSI), diffusionweighted imaging (DWI) and conventional T2-weighted images (T2WI). The purpose of this article is to review the role of mpMRI in detecting local recurrence of PCa in patients after RP.

\section{Multiparametric Magnetic Resonance Technic}

Mp-MRI consists of a combination of high-resolution T2 WI, DWI and DCE-MR and optionally MRSI. Different approaches have been developed for mp-MRI including at least two of the following functional imaging sequences in addition to T2WI: DWI, MRSI and DCE-MRI. One of the advantages of mp-MRI is 
that it can provide both anatomic and functional information as non-invasive or minimally invasive. The addition of DCE to T2WI with endorectal coil was found to be effective for determining local tumor recurrence after RP. The imaging method is quite successful in distinguishing the contrast between cancerous tissue and non-cancerous soft tissue [10-15]. Nowadays, because of the pratical and simple use and at the same time because of it does not require exogenous contrast material administiration, interest in DWI which is a new technic has increased [16]. DWI is also found to be useful in detecting of prostate carcinoma before treatment and recurrence after RT $[17,18]$. However, the role of DWI in the diagnosis of recurrent tumor in the prostatectomy bed is limited [19-22]. In mp-MRI, a large number of parameters are examined, so it is difficult to artificially integrate and interpret information in such a large amount. In clinical practice, PI-RADS v2 based on mp-MRI is currently used for PCa diagnosis. Despite developing techniques, however, recent studies have reported that PI-RADS v2 still has limited capacity both in the prediction of gleason score and diagnosis of PCa [23-25]. PI-RADS v2 scoring table is summarized in (Figure 1) [26].

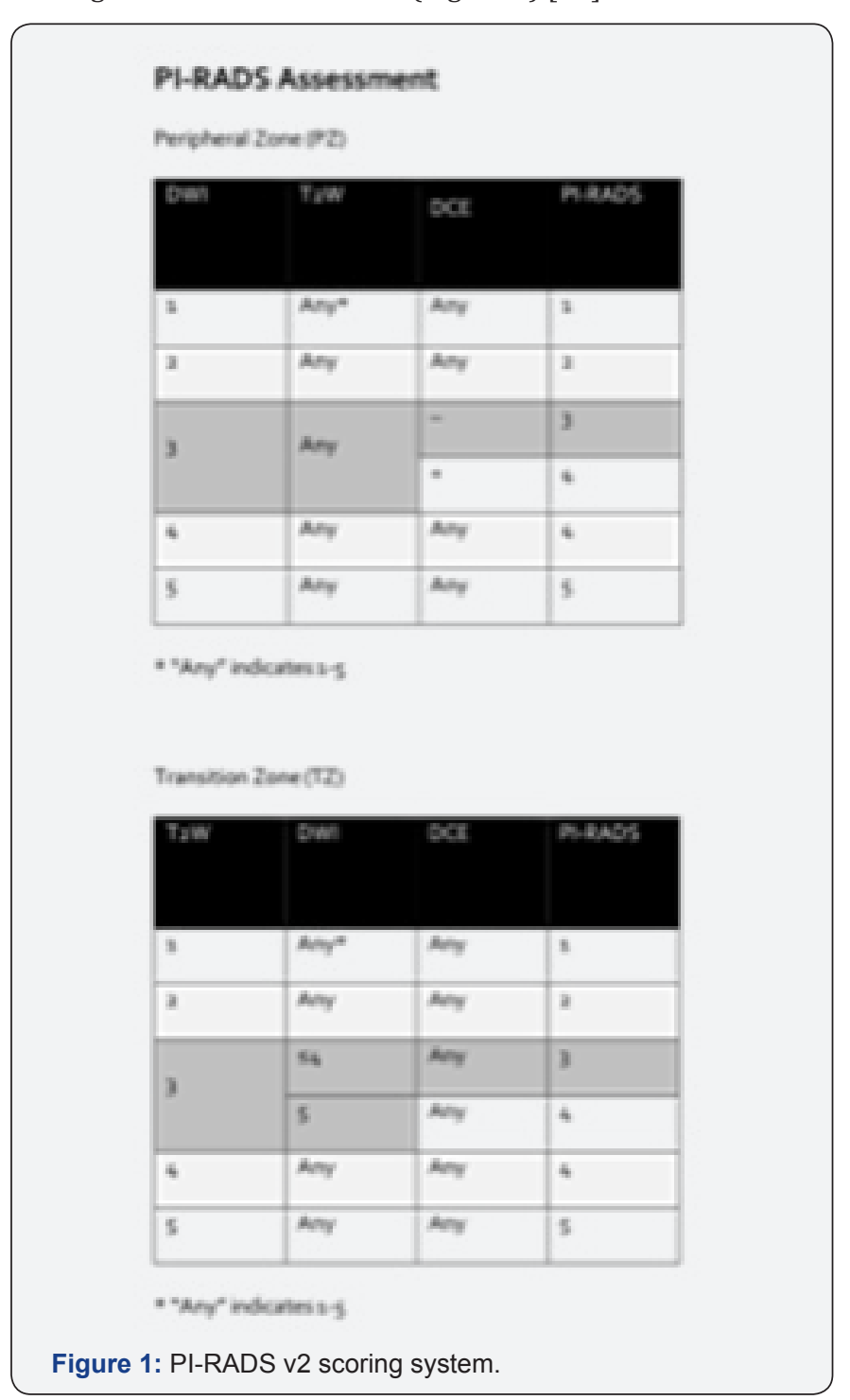

\section{Clinic Importance of mp-MRI after Radical Prostatectomy}

The measurement of serum PSA is the basic parameter used to follow-up of patients with PCa after treatment. Up to day, Computerized tomography, bone scintigraphy and transrectal ultrasound guidance biopsy are commonly used to detect localized recurrent prostate cancer or metastatic disease, but these methods are not sensitive enough and accurate. Recently, several studies reported promising results of mp-MRI in detecting local recurrence after RP. A rapidly increasing PSA level or a PSA derivative (i.e. high PSA rate and short PSA doubling time) usually indicates the presence of distant metastases, while a slow and progressive increase in serum PSA concentration is usually due to local recurrent disease. Although increasing serum PSA levels indicate the BCR after RP, it could be results of residual benign prostatic tissue in the surgical margin, as well as local recurrent PCa or distant metastasis. One study reported that $61 \%$ of patients had benign prostate tissue in the prostate bed may theoretically influence PSA-free, metastases-free, disease-specific, and overall survival in prostate cancer patients [6].

Salvage RT of the prostatic bed or anastomotic field may be curative treatment for patients with local recurrence PCa. Patients with distant metastases are unlikely to benefit from sRT alone, and radiation-related side effects may impair quality of life. There is no consensus on when sRT treatment should be performed in patient with PCa who does not receive adjuvant RT. According to National Comprehensive Cancer Network (NCCN) guidelines "sRT is most effective if pre-treatment PSA level is $<0.5 \mathrm{ng} / \mathrm{ml}$ "; however, patients must be treated if an undetectable PSA that becomes detectable and then increases on 2 subsequent measurements" [27]. European Association of Urology guidelines advise sRT before the PSA level increases to $0.5 \mathrm{ng} / \mathrm{ml}$ [28], and the American Society for Radiation Oncology/ American Urological Association guidelines recommended sRT at earliest sign of PSA recurrence after undetectable PSA has been achieved [29]. Recurrent tumors after RP can be observed in different forms such as uni- or multi-lobulated masses, semicircumferential masses, or plaque-like soft tissue thickening in the anastomotic bed. Recurrent masses, after RP can develop into anywhere in the prostatectomy bed such as the bladder wall, retrovesical space, vesicourethral anastomosis, and membranous urethra [13]. According to the recent literature, local recurrent disease was detected in a PSA level of around $0.8-1.3 \mathrm{ng} / \mathrm{ml}$ in a large-populated studies $[21,30]$. In detecting local recurrence after RP, T2-weighted imaging is characterized by low sensitivity (48-61\%) and specificity (52-82\%); Post-operative scarring can lead to false-positives results in situations where it has a nodular appearance mimicking recurrences. In the suspect of between local recurrens and fibrosis, DCE-MR may be a valuable functional technique to distinguish between normal prostatic tissue residues and fibrosis with PCa recurrence in the prostatic field. When combined with T2-weighted imaging, the sensitivity and specificity of DCE-MRI in detecting local recurrences after RP 
are $79-88 \%$ and $89-100 \%$, respectively $[11,21]$. Seminal vesicle invasion is observed in $20 \%$ of patients and may mimic local recurrent disease. Normal retained seminal vesicles will appear as hyperintense fluid filled tubules in the superior aspect of the prostatectomy bed but will not show abnormal enhancement on DCE MRI, nor show restricted diffusion, distinguishing this finding from recurrent tumor. If SVs are still retained despite seminal vesicle invasion (SVI), they will show hypointense signal and early amplification on ADC maps and DCE MR, respectively [31]. Various results have been obtained in the literature regarding DW MRI in terms of detecting local recurrent disease. However, but it can be beneficial in this sense if it is carefully and correctly interpreted. For example, it may be useful to prevent misdiagnosis due to contrast-enhanced peri-prosthetic vessels mimicking nodular local recurrent mass. Panebianco reported in his study that the combination of T2W MRI and DCE MRI showed 98\% sensitivity, 94\% specificity, and 93\% accuracy in detecting local recurrence [21].

\section{Conclusion}

Nowadays, mp-MRI is an increasingly used imaging technique that is very useful in detecting recurrent PCA in patients following RP thanks to developing technology. Early detection of local recurrens after RP is essential for the management of treatment success and patient survival. Althouh T2W MRI is usually positive in patients with BCR, it is less sensitive than other techniques. DCE-MRI is the most beneficial technic in this sense. Despite the difficulties in practice and interpretation, with the increasing number of studies and rapidly developing technologies, we believe that mp-MRI will take place in guidelines to detect local recurrences after radical prostatectomy and it will be used in practice increasingly for the follow-up of such patients in the future.

\section{References}

1. Partin AW, Pound CR, Clemens JQ, Epstein JI, Walsh PC (1993) Serum PSA after anatomic radical prostatectomy. The Johns Hopkins experience after 10 years. Urol Clin North Am 20(4): 713-725.

2. Mertan FV, Greer MD, Borofsky S, Kabakus IM, Merino MJ, et al. (2016) "Multi-parametric Magnetic Resonance Imaging of Recurrent Prostate Cancer." Topin magn reson imaging 25(3) : 139-147.

3. Han M, Partin AW, Zahurak M, Piantadosi S, Epstein JI, et al. (2003) Biochemical (prostate specific antigen) recurrence probability following radical prostatectomy for clinically localized prostate cancer J Urol 169(2): 517-523.

4. Freedland SJ, Mangold LA, Walsh PC, Partin AW (2005) The prostatic specific antigen era is alive and well: prostatic specific antigen and biochemical progression following radical prostatectomy. J Urol 174(4 pt 1): 1276-1281.

5. Toussi A, Stewart-Merrill SB, Boorjian SA, Psutka SP, Thompson RH, et al. (2016) Standardizing the definition of biochemical recurrence after radical prostatectomy - what prostate specific antigen cut point best predicts a durable increase and subsequent systemic progression? J Urol 195(6): 1754-1759.

6. Pound CR, Partin AW, Eisenberger MA, Chan DW, Pearson JD, et al. (1999) Natural history of progression after PSA elevation following radical prostatectomy. JAMA 281(17): 1591-1597.
7. Taylor N, Kelly JF, Kuban DA, Babaian RJ, Pisters LL, et al. (2003) Adjuvant and salvage radiotherapy after radical prostatectomy for prostate cancer. Int J Radiat Oncol Biol Phys 56: 755-763.

8. Wiegel T, Bottke D, Steiner U, Siegmann A, Golz R, et al. (2009) Phase III postoperative adjuvant radiotherapy after radical prostatectomy compared with radical prostatectomy alone in pT3 prostate cancer with postoperative undetectable prostate-specific antigen: ARO 9602/AUO AP 09/95. J Clin Oncol 27(8): 2924-2930.

9. Cornford P, Bellmunt J, Bolla M, et al. (2017) EAU-ESTRO-SIOG guidelines on prostate cancer. Part II: treatment of relapsing, metastatic, and castration-resistant prostate cancer. Eur Urol 71(4): $630-42$.

10. Vargas HA, Wassberg C, Akin O, Hricak H (2012) MR imaging of treated prostate cancer. Radiology 262(1): 26-42.

11. Casciani E, Polettini E, Carmenini E, Floriani I, Masselli G, et al. (2008) Endo- rectal and dynamic contrast-enhanced MRI for detection of local recurrence after radical prostatectomy. AJR 190(5): 1187-1192.

12. Sciarra A, Panebianco V, Salciccia S, Osimani M, Lisi D, et al. (2008) Role of dynamic contrast-enhanced magnetic resonance (MR) imaging and proton MR spectroscopic im aging in the detection of local recurrence after radical prostatectomy for prostate cancer. Eur Urol ; 54: 589-600.

13. Cirillo S, Petracchini M, Scotti L, Gallo T, Macera A, et al. (2009) Endo- rectal magnetic resonance imaging at 1.5 Tesla to assess local recurrence following radical prostatectomy using T2-weighted and contrast-en- hanced imaging. Eur Radiol 19(3): 761-769.

14. Boonsirikamchai P, Kaur H, Kuban DA, Jackson E, Hou P (2012) Use of maximum slope images generated from dynamic contrast-enhanced MRI to detect locally recurrent prostate carcinoma after prostatectomy: a practical approach. AJR am j Roentqenol 198(3): W228-W236.

15. Wassberg C, Akin O, Vargas HA, Shukla-Dave A, Zhang J, et al. (2012) The incremental value of con- trast-enhanced MRI in the detection of biopsy- proven local recurrence of prostate cancer after radical prostatectomy: effect of reader experience. AJR 199(2): 360-366.

16. Somford DM, Fütterer JJ, Hambrock T, Barentsz JO (2008) Diffusion and perfusion MR imaging of the prostate. Magn Reson Imaging Clin N Am 16(4): 685-695.

17. Donati OF, Jung SI, Vargas HA, Gultekin DH, Zheng J, et al. (2013) Multipara- metric prostate MR imaging with T2-weighted, diffusionweighted, and dynamic contrast-enhanced sequences: are all pulse sequences neces- sary to detect locally recurrent prostate cancer after radiation therapy? Radiology 268(2): 440-450.

18. Morgan VA, Riches SF, Giles S, Deanaley D, deSouza NM (2012) Diffusion-weighted MRI for local- ly recurrent prostate cancer after external beam radiotherapy. AJR 198(3): 596-602.

19. Liauw SL, Pitroda SP, Eggener SE, Stadler MS, Pelizzari CA, et al. (2013) Evalua- tion of the prostate bed for local recurrence after radical prostatectomy using endorectal magnetic resonance imaging. Int J Radiat Oncol Biol Phys 85(2): 378-384.

20. Panebianco V, Sciarra A, Lisi D, Galati F, Buonocore V, et al. (2012) Prostate cancer: 1HMRS-DCEMR at $3 \mathrm{~T}$ versus [(18)F] choline PET/ CT in the detection of local prostate cancer recurrence in men with biochemical pro- gression after radical retropubic prostatectomy (RRP). Eur J Radiol 81(4): 700-708.

21. Panebianco V, Barchetti F, Sciarra A, Musio D, Forte V, et al. (2013) Prostate cancer recurrence after radical prostatectomy: the role of 3-T diffusion imaging in multi- parametric magnetic resonance imaging. Eur Radiol 23(6): 1745-1752.

22. Roy C, Foudi F, Charton J, Jung M, Lang H, et al. (2013) Comparative sensitivities of functional MRI sequences in detection of local recurrence of prostate carcinoma after radical prostatectomy or external-beam radiotherapy. AJR am j Roentqenol 200(4): W361-W368. 
23. Becker AS, Cornelius A, Reiner CS, Stocker D, Ulbrich EJ, et al. (2017) Direct comparison of PI-RADS version 2 and version 1 regarding interreader agreement and diagnostic accuracy for the detec- tion of clinically significant prostate cancer. Eur J Radiol 94: 58-63.

24. Benndorf M, Hahn F, KronigM, Jilg CA, Krauss I, et al. (2017) Diagnostic performance and reproducibility of $\mathrm{T} 2 \mathrm{w}$ based and diffusion weighted imaging (DWI) based PI-RADSv2 lexicon descriptors for prostate MRI. Eur J Radiol 93: 9-15.

25. Polanec S, Helbich TH, Bickel H, Pinker-Domenig K, Georg D, et al (2016) Head-to-head comparison of PI-RADS v2 and PI-RADS v1. Eur ] Radiol 85(6): 1125-1131.

26. (2015) Prostate Imaging and Reporting and Data System: Version 2 PI-RADS Steering Committee, p: 18.

27. NCCN Clinical Practice Guidelines in Oncology (NCCN Guideline) Prostate Cancer.

28. Heidenreich A, Bastian PJ, Bellmunt J, Bolla M, Joniau S, et al. (2-14) EAU guidelines on prostate cancer. Part ii: Treatment of advanced, relapsing, and castration-resistant prostate cancer. Eur Urol 65(2): 467-479.

29. Valicenti RK, Thompson I, Albertsen P, Davis BJ, Goldenberg SL (2013) Faraday MM and American Society for Radiation Oncology/ American Urological A: Adjuvant and salvage radiation therapy after prostatectomy: American Society for Radiation Oncology/American Urological Association guidelines. Int J Radiat Oncol Biol Phys 86(5): 822-828.

30. Alfarone A, Panebianco V, Schillaci O, Salciccia S, Cattarino S, et al. (2012) Comparative analysis of multiparametric magnetic resonance and PET-CT in the management of local recurrence after radical prostatectomy for prostate cancer. Crit Rev Oncol Hematol 84(1): 109121.

31. Sella T, Schwartz LH, Hricak H (2006) Retained seminal vesicles after radical prostatectomy: frequency, MRI characteristics, and clinical relevance. AJR American journal of roentgenology 186(2): 539-546.

\section{Your next submission with Juniper Publishers will reach you the below assets}

- Quality Editorial service

- Swift Peer Review

- Reprints availability

- E-prints Service

- Manuscript Podcast for convenient understanding

- Global attainment for your research

- Manuscript accessibility in different formats

( Pdf, E-pub, Full Text, Audio)

- Unceasing customer service

Track the below URL for one-step submission https://juniperpublishers.com/online-submission.php 